Published in final edited form as:

Du, Q., Zhang, S., Antonietti, M., \& Yang, F. (2020). Sustainable leaching process of phosphates from animal bones to alleviate the world phosphate crisis. ACS Sustainable Chemistry \& Engineering, 8(26), 9775-9782. doi:10.1021/ acssuschemeng.0c02233.

\title{
Sustainable leaching process of phosphates from animal bones to alleviate the world phosphate crisis
}

\author{
Q. Du, S. Zhang, M. Antonietti, F. Yang
}

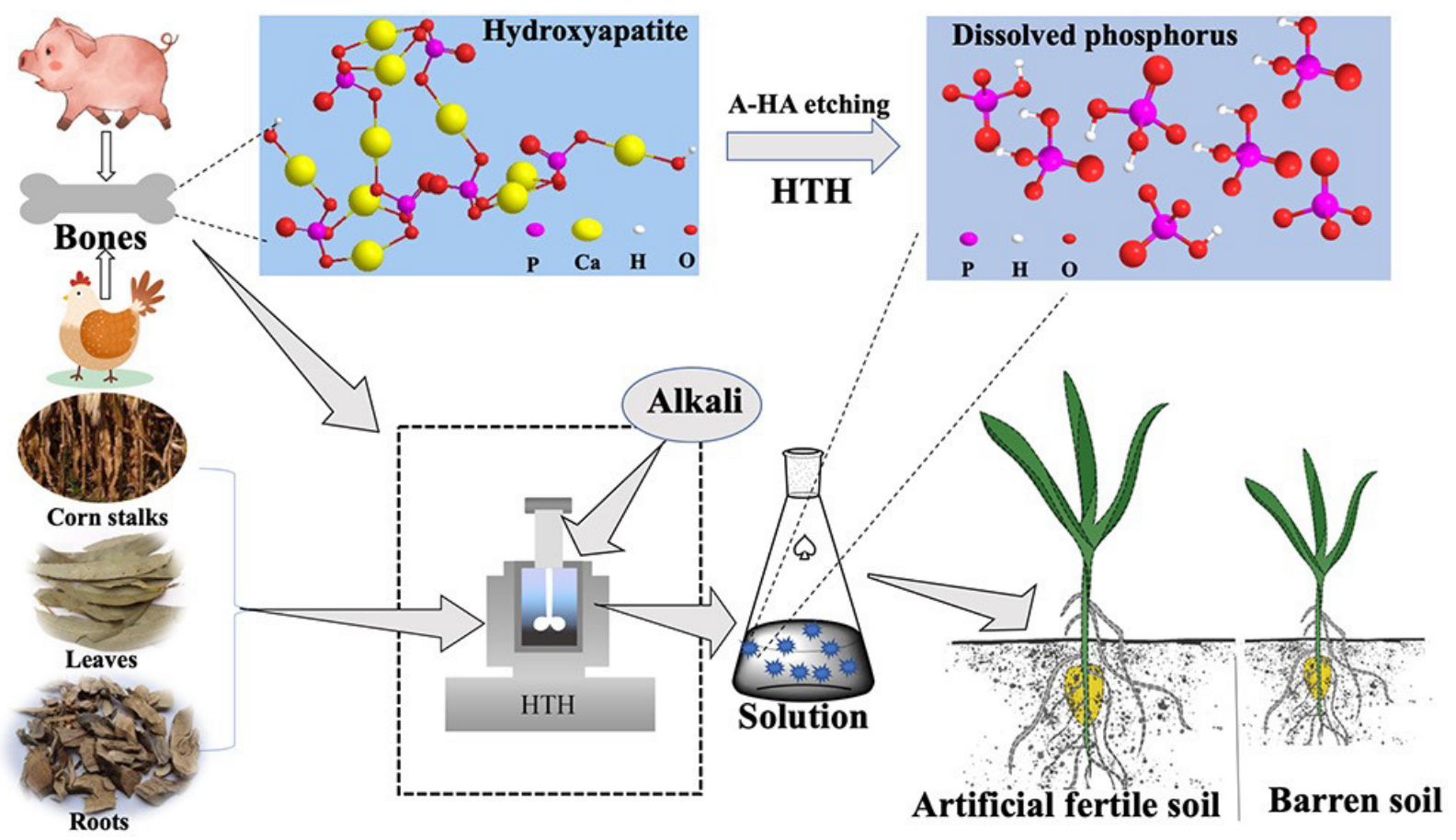

Pot-planting experiments show that the resulting liquids were applied as a fertilizer and led to a significant promotion of the growth of seedlings. 


\title{
A sustainable leaching process of phosphates from animal bones to alleviate the world phosphate crisis
}

\author{
Qing Du ${ }^{1 \dagger, \sharp}$, Shuaishuai Zhang ${ }^{1 \dagger}$, Markus Antonietti ${ }^{\S, \#}$, Fan Yang ${ }^{\dagger, \downarrow, *}$ \\ $\dagger$ Joint Laboratory of Northeast Agricultural University and Max Planck Institute \\ of Colloids and Interfaces (NEAU-MPICI), Harbin 150030, China. \\ \$Shool of Water Conservancy and Civil Engineering, Northeast Agricultural \\ University, Harbin 150030, China. \\ $\$$ Max Planck Institute of Colloids and Interfaces Department of Colloid Chemistry \\ 14476 Potsdam (Germany). \\ *Corresponding author: yangfan_neau@163.com \\ \# Corresponding author: Markus.Antonietti@mpikg.mpg.de \\ 1-co-first author
}

\section{ABSTRACT:}

Lack of available phosphorus (P) minerals and their very localized regional distribution threatens world food production. Traditional farming methods that recycle various biological wastes and manure for localized fertilization of farmland are our role model, but come with risks such as hygiene, water toxification and passed-on diseases. Here, we present a bran-new hydrothermal process which turns animal bones of kitchen wastes into secondary $\mathrm{P}$ sources for fertilization, showing that this hydrothermal humification $(\mathrm{HTH})$ process under $200{ }^{\circ} \mathrm{C}$ for $24 \mathrm{~h}$ completely disintegrates chemical structure of the biomass, while the simultaneously in-situ prepared artificial humic acid 
(A-HA) etches even macroscopic bones. Notably, A-HA can solubilize the insoluble P existing in animal bones partly as directly dissolved phosphorus (DP), accounting for $6.36 \%$ of total phosphorus (TP) in the bone wastes. Characterization methods indicate that oxygen-containing functional groups (i.e., - $\mathrm{COOH}$ and phenolic-OH) of A-HA can help to corrode bones, causing $\mathrm{Ca}_{5}\left(\mathrm{PO}_{4}\right)_{3}(\mathrm{OH})$ to be decomposed into a large number of more active P minerals, furthermore, leading to high DP $(96.79 \mathrm{mg} / \mathrm{L})$ content and the formation of new P-based species. Pot planting experiments show that the resulting liquids were applied as a fertilizer and lead to a significant promotion of the growth of seedlings.

KEYWORDS: Animal bones; Artificial humic acid; Phosphorus recovery; Solubilization; Plant growth.

\section{INTRODUCTION}

Phosphorus (P) is one of the crucial elements in the biosphere, controlling life activities such as energy conversion and expression of genetic information ${ }^{1-2}$. Every year, China, the United States, Morocco, and other countries mine millions of tons of $\mathrm{P}$ from the ground, most of which is turned into fertilizer for food crops ${ }^{3}$. As the world's population continues to increase, the demand for $\mathrm{P}$ grows. However, phosphate deposits with low cadmium/uranium content have been consumed, the available deposits will not be able to meet the urgent needs of humanity ${ }^{4-5}$. Experts speculate that mineable deposits may disappear within a century ${ }^{3,6}$. Therefore, agricultural engineering must address problems such as low utilization rate of $\mathrm{P}$ fertilizer and excessive consumption 
of $\mathrm{P}$ rock resources to promote world food security ${ }^{7}$.

On the other hand, $\mathrm{P}$ is not exactly a rare element and very abundant in soil, accounting for about $50 \mathrm{mg} / \mathrm{kg}$ to $1500 \mathrm{mg} / \mathrm{kg}$ of its total composition ${ }^{8-9}$. However, most of this $\mathrm{P}$ is tightly bound to multivalent metal species (i.e., aluminum or iron) to form insoluble phosphates, having low bioavailability in soil ${ }^{10-11}$. Many studies have pointed out that soil contains abundant organic matters (i.e., humic acid) which contribute to phosphate dissolution and recalcination equilibria ${ }^{12}$. Especially in black soils, the amount of highly active organic matter is significant, providing a comfortable growth and reproduction environment for plants ${ }^{13-14}$. Humic acid (HA) contains rich oxygen-containing acidic functional groups (i.e., phenolic-OH, - $\mathrm{COOH}$, etc.) $)^{15-16}$, which can donate electrons to dissolve the stable multivalent metal phosphate in the soil under the action of photocatalysis or microorganisms ${ }^{17-18}$, improving solubility of otherwise insoluble $\mathrm{P}$. Our previous work $^{19}$ described a practicable route for solubilization of otherwise insoluble $\mathrm{P}$ minerals by application of artificial humic substances in detail. We found that the morpho-synthetic changes were not only due to the classical mechanisms of organic acid etching, but also related to the polymer nature of HA and involved redox processes, all driven by artificial humic substances.

According to the statistics of the Food and Agriculture Organization of the United Nations (FAO), in 2013, the world's total meat consumption was about 3024 million tons, with an annual increase of $2.4 \%$, with pork and poultry accounting for about $1 / 2$ (http://www.fao.org/faostat/en/\#data). With the large consumption of meat products, 
bones are a hundred million tons waste products, which are usually burned or land filled as kitchen wastes ${ }^{20}$, leading to potential environmental pollution. Worth noting, bones are made up from hydroxyapatite, a defined $\mathrm{P}$ mineral that can be considered as a circular P sources for sustainable P recovery. Currently, Someus and Postma et al $\mathrm{l}^{21-22}$. developed a specific zero emission autothermal carbonization system for recovering phosphorus from animal bones. The solid product obtained is animal bone chars (ABC) concentrated with $>30 \%$ phosphorus pentoxide $\left(\mathrm{P}_{2} \mathrm{O}_{5}\right)$, making it an innovative fertilizer. Darwish et $\mathrm{al}^{23}$. used acid leaching technology to recover $\mathrm{P}$ in waste fish bone ashes for removal of $\mathrm{NH}_{4}-\mathrm{N}$.

Kitchen wastes, in line with the principles of waste utilization, environmental protection and sustainable development, needs to be dealt with in a clean, low energy, highly efficiently engineering process, also excluding biological hazards. The primary intention of this research was to provide new ideas for contributing to the problem of closing the phosphate loop and an analysis on the utilization of such phosphate preparations in agriculture.

\section{MATERIALS AND METHODS}

\section{Materials and Reagents}

Chicken bones $(\mathrm{CB})$ and pork bones $(\mathrm{PB})$ were collected from the canteens of Northeast Agricultural University. Waste bones were repeatedly cleaned with deionized water to remove impurities, dried at $80{ }^{\circ} \mathrm{C}$ for $24 \mathrm{~h}$, and then simply broken into small pieces in order to be able to place them in the reactor. Corn stalks (CS) were collected 
on the campus of Northeast Agricultural University, and eucalyptus leaves (L) and tea roots (R) were purchased from Anhui Province, then CS, L, and R were washed with deionized water several times, dried, pulverized, and passed through a 100-mesh sieve to obtain biomass powders. The barren soil was collected in the long-term wasteland on the campus of Harbin Engineering University, air-dried, and removed impurities. Then the barren soil was passed through a 40-mesh sieve, stored for later experiments, and the methods of soil $\mathrm{P}$ were listed in Supporting Information. Alkali ash (AA) was collected from a factory in Hubei Province, and potassium hydroxide $(\mathrm{KOH})$, calcium hydroxide $\left(\mathrm{Ca}(\mathrm{OH})_{2}\right)$, sulfuric acid $\left(\mathrm{H}_{2} \mathrm{SO}_{4}\right)$, hydrochloric acid $(\mathrm{HCl})$, and perchloric acid $\left(\mathrm{HClO}_{4}\right)$ were purchased by Tianjin Chemical Reagent Co., Ltd., China. All reagents and chemicals were used as received without further purification. Deionized water $\left(18.8 \mathrm{M} \Omega \cdot \mathrm{cm}^{-1}\right)$ was used for all experiments.

\section{PROCEDURES}

Briefly, $2.4 \mathrm{~g}$ plant biomass ( $\mathrm{L}$ and $\mathrm{R}$ ) powder, $1.2 \mathrm{~g}$ bones (CB and $\mathrm{PB}$ ) and the required amount of $\mathrm{KOH}$ solution were placed in a $100 \mathrm{~mL}$ Teflon-lined stainless-steel autoclave at $200^{\circ} \mathrm{C}$ for different times $(16 \mathrm{~h}, 24 \mathrm{~h}$, and $48 \mathrm{~h}$ ). Thereafter, the autoclave was cooled to room temperature, and solids and liquids of the product were obtained and stored separately for further testing and characterizations. In order to further reduce the cost and sustainability of the process, AA and $\mathrm{Ca}(\mathrm{OH})_{2}$ were used instead of $\mathrm{KOH}$ (according to the classical process of caustification) as follows: $2.4 \mathrm{~g}$ biomass (CS) powders, $1.2 \mathrm{~g}$ bones $(\mathrm{CB}$ and $\mathrm{PB})$, and the required $\mathrm{AA}$ and $\mathrm{Ca}(\mathrm{OH})_{2}$ were placed in a 
$100 \mathrm{~mL}$ polytetrafluoroethylene-lined stainless-steel autoclave and then reacted at $200{ }^{\circ} \mathrm{C}$ for $48 \mathrm{~h}$ (explained below). Thereafter, the autoclave was cooled to room temperature, and solids and liquids of the product were obtained $(\mathrm{pH}=7 \sim 8)$ and stored separately for testing and characterization, wherein the liquid product was used for direct application to soil samples for pot experiments. All bones extraction $\mathrm{P}$ concentrations are shown as the average \pm standard deviation.

Small square plastic pots (caliber $7 \mathrm{~cm}$ ) were used to perform pot experiments in a warm light gradient incubator (simulating the length of the day, the temperature and light intensity were $16 \mathrm{~h}, 25^{\circ} \mathrm{C}$, and $60 \%$, respectively. Simulating the length of night, temperature and light intensity are $8 \mathrm{~h}, 18{ }^{\circ} \mathrm{C}$, and $0 \%$ respectively). Corn as main food crops in the northeast of China was selected because of its fast growth rate, high germination rate, and highly sensitive plant's phosphorus deficiency ${ }^{24}$. The experimental process was as follows: $200 \mathrm{~g}$ sieved barren soils mixed with or without liquid products obtained from $\mathrm{HTH}$ reaction (a certain amount of bones, different biomass, $\mathrm{KOH}$ or AA and demonized water in $50 \mathrm{~mL}$ hydrothermal reactor) thoroughly to get artificial fertile soil for corn planting. Two corn seeds after being screened and aseptically treated were planted in each pot (setting up 3 parallel groups), and rhizosphere soil were taken at different time points to test soil available phosphorus (AP) $(1,3,7$, and 11 days) and harvested after 22 days. Fresh and dry plant weight were calculated by weighing, and the lengths of roots, stems, and plants were measured by a ruler. 
Microstructure, composition, and physicochemical properties of bone-based samples were characterized by Scanning Electron Microscopy (SEM, ZEISS SUPRA40), X-ray Diffraction analysis (XRD, Rigaku TTR III using Cu Ka radiation), Fourier Transform Infrared Spectrometry (FTIR, Thermo Fisher Scientific, USA), Xray Photoelectron Spectroscopy (XPS, Thermo ESCALAB 250) and Elemental Analyzer (Flash Smart NCHS-O). Besides, Inductively Coupled Plasma-Atomic Emission Spectrometry analysis (ICP-AES) was used to detect DP and AP in soil and liquids and $\mathrm{P}$ contents in the calculated bone samples after digestion by $\mathrm{HNO}_{3}, \mathrm{HF}$ and $\mathrm{HClO}_{4}$ solutions.

\section{RESULTS AND DISCUSSION}

In previous work ${ }^{25}$, we successfully synthesized artificial humic substances (AHA and A-FA) having high similarity with natural extracts by a novel HTH technology. In this paper, it is shown that the low-solubility hydroxy-phosphate minerals (i.e., $\left.\mathrm{Ca}_{5}\left(\mathrm{PO}_{4}\right)_{3}(\mathrm{OH})\right)$ in animal bones are effectively etched and recrystallized to release DP and AP. Characterization of morphologic changes in bones before and after the HTH process are realized by advanced Scanning Electron Microscopy. Comparing Fig. 1a-f with Fig. S1 (supporting information), the surfaces of PB and CB before A-HA etching are smooth and textured, however, after being subjected to HTH treatment, the surfaces became rough, forming velvet-like morphologies. Very worth reporting, the bones become very brittle and could even manually be powered to fine grains, i.e., the bones lost their complete mechanical cohesion. 
In our previous publications ${ }^{19,26-27}$, it has been proposed and demonstrated that AHA was rich in oxygen-containing acidic functional groups such as $-\mathrm{COOH}$, phenolic$\mathrm{OH}$ etc., which can provide a strong etching ability for solubilizing insoluble P. In order to describe the profound difference between diverse biomass species and the ability of their products for etching, originally $\mathrm{FePO}_{4}$ with a perfect crystal surface were chosen as an example, and the images after $\mathrm{HTH}$ reaction with the introduction of different biomass are recapitulated in Fig. S2 (supporting information). As concluded in Table S1 (supporting information), the significant difference in structure is due to the different types and quantities of acidic oxygen-containing functional groups being present in AHA.

A comparison of EDX patterns (Fig. S3, supporting information) reveals details of the etching mechanisms. In general, the anionic functional groups of A-HA (i.e., $\mathrm{COOH}$, phenolic-OH, etc.) compete with phosphate ions for the binding of $\mathrm{Ca}^{2+}$ ions $^{28}$, so that we can simultaneously observe bone dissolution A-HA and $\mathrm{Ca}^{2+}$ complexes, as well as recrystallization towards new species found as crystals on the surface of bones (Fig. 1). Under the same conditions, A-HA produced from different biomass etched the bones differently, leading to different Ca contents on the bone's surfaces. For instance, the amount of released DP from $\mathrm{CB}$ after R-AHA (A-HA from roots) etching is significantly larger than that resulted from L-AHA (A-HA from leaves) sample (96.79 $\pm 2.54 \mathrm{mg} / \mathrm{L}$ versus $24.24 \pm 1.44 \mathrm{mg} / \mathrm{L})$. 


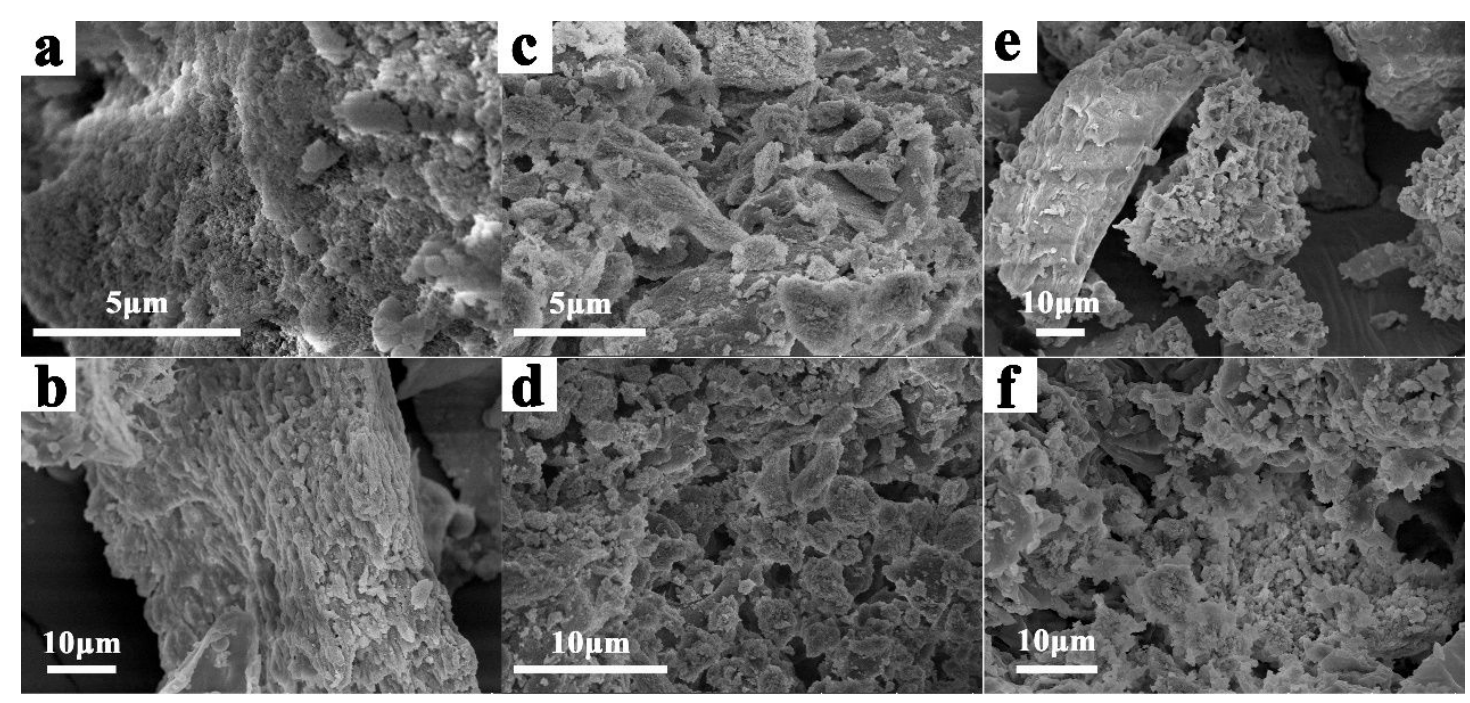

Fig. 1. SEM images of PB (a, c, e) and CB (b, d, f) etched with A-HA from roots, leaves and corn stalks, respectively.

To further analyze the process of A-HA decay and etching of animal bones, XRD analysis was applied to reveal details of a series of bone-based residues obtained at different conditions including bones ( $\mathrm{CB}$ and $\mathrm{PB})$, biomass $(\mathrm{R}, \mathrm{L}$, and $\mathrm{CS})$, and reaction time (16 h, $24 \mathrm{~h}$, and $48 \mathrm{~h}$ ). We intend to describe the strong interaction between A-HA and animal bones and the dynamics of the structural rearrangements; the relative results are shown in Fig. 2. In the $\mathrm{CB}+\mathrm{L} / \mathrm{R}+\mathrm{KOH}$ series, five strong diffraction peaks appeared on the etched bones: $25.88^{\circ}, 31.77^{\circ}, 39.81^{\circ}, 46.71^{\circ}$, and $49.47^{\circ}$, corresponding to diverse planes of $\mathrm{Ca}_{5}\left(\mathrm{PO}_{4}\right)_{3}(\mathrm{OH})\left(\begin{array}{lll}0 & 0 & 2\end{array}\right),\left(\begin{array}{lll}2 & 1 & 1\end{array}\right),\left(\begin{array}{lll}3 & 1 & 0\end{array}\right),\left(\begin{array}{ll}2 & 2\end{array}\right)$, and (2 113 ) (JCPDS, No.09-0432) $)^{29-30}$, respectively. Three strong diffraction peaks at $29.55^{\circ}$, $31.82^{\circ}$, and $37.93^{\circ}$ correspond to the crystal planes of $\mathrm{CaCO}_{3}\left(\begin{array}{l}2 \\ 2\end{array}\right)$ ), (2 21$)$, and (2 3 0) (JCPDS, No.17-0763) ${ }^{31}$, respectively. In addition, with the increase of reaction time, the peak intensity assigned to $\mathrm{Ca}_{5}\left(\mathrm{PO}_{4}\right)_{3}(\mathrm{OH})$ existed in the bone gradually decreased, suggesting dissolution of $\mathrm{Ca}_{5}\left(\mathrm{PO}_{4}\right)_{3}(\mathrm{OH})$, which was attributed to the strong interaction 
between A-HA and bones. The detection of a large amount of soluble P in the solution after the HTH reaction furthermore proved the conversion of insoluble P minerals into dissolved or amorphous P species, which will be reported later in this article. Notably, other new $\mathrm{P}$ species such as $\mathrm{Ca}_{3}\left(\mathrm{PO}_{4}\right)_{2} \cdot \mathrm{xH}_{2} \mathrm{O}$ can be found according to their strong diffraction peaks located at $25.88^{\circ}, 31.94^{\circ}, 32.90^{\circ}, 46.79^{\circ}$ and $49.50^{\circ}$ (JCPDS, No. 18 0303). In addition, the application of alternative, more sustainable raw materials (CS, AA, and $\mathrm{Ca}(\mathrm{OH})_{2}$ ) as a strategy for etching bones also released a large amount of soluble P. This shows that etching bones with A-HA in general converts insoluble $\mathrm{P}$ in the bones into soluble $\mathrm{P}$, and as such the $\mathrm{P}$ can be sustainably cycled, which has great significance and a wide applicability.

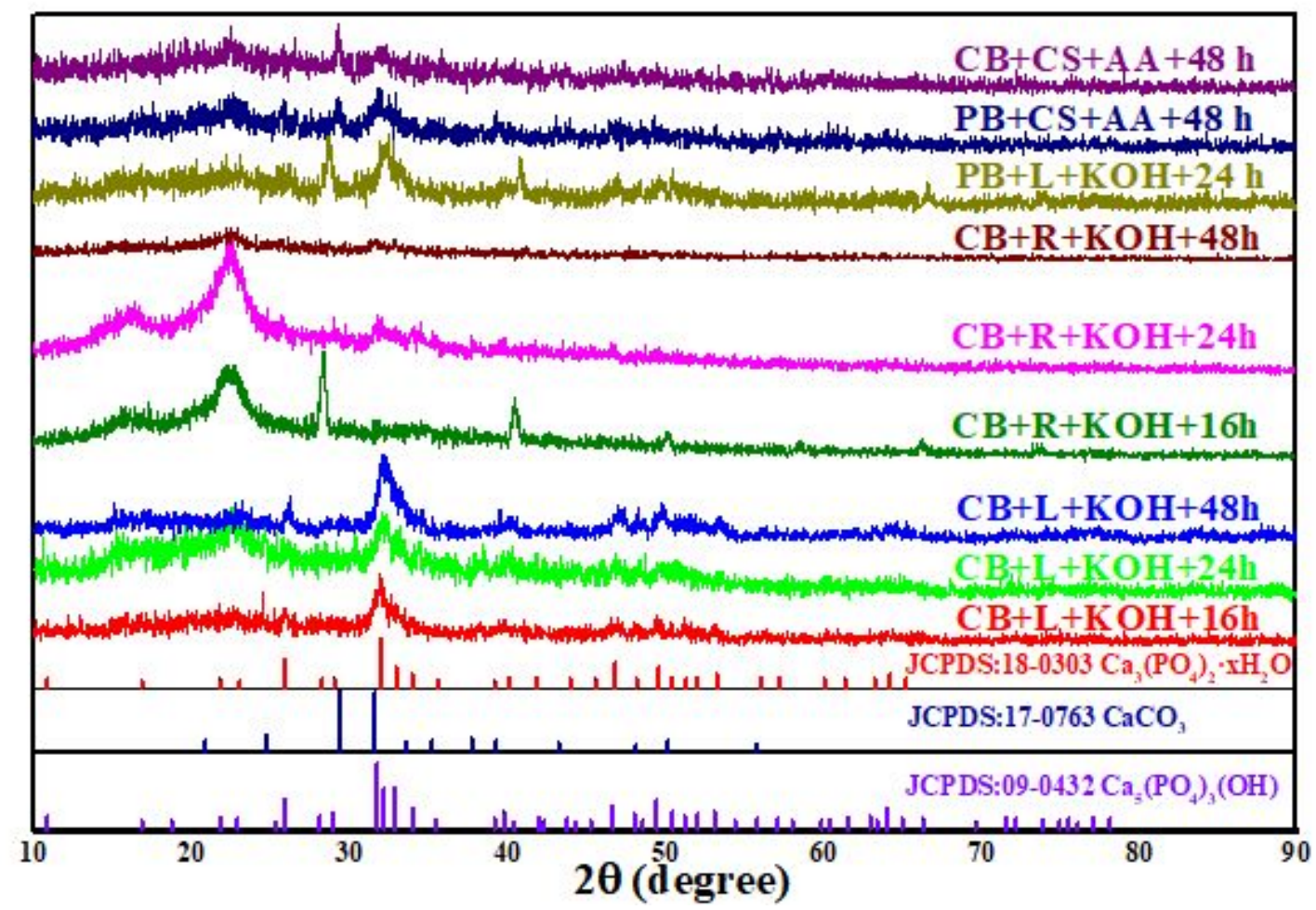

Fig. 2. XRD comparison of different bones (CB and PB) etched by A-HA from different biomass (leaves, roots, corn stalks) 

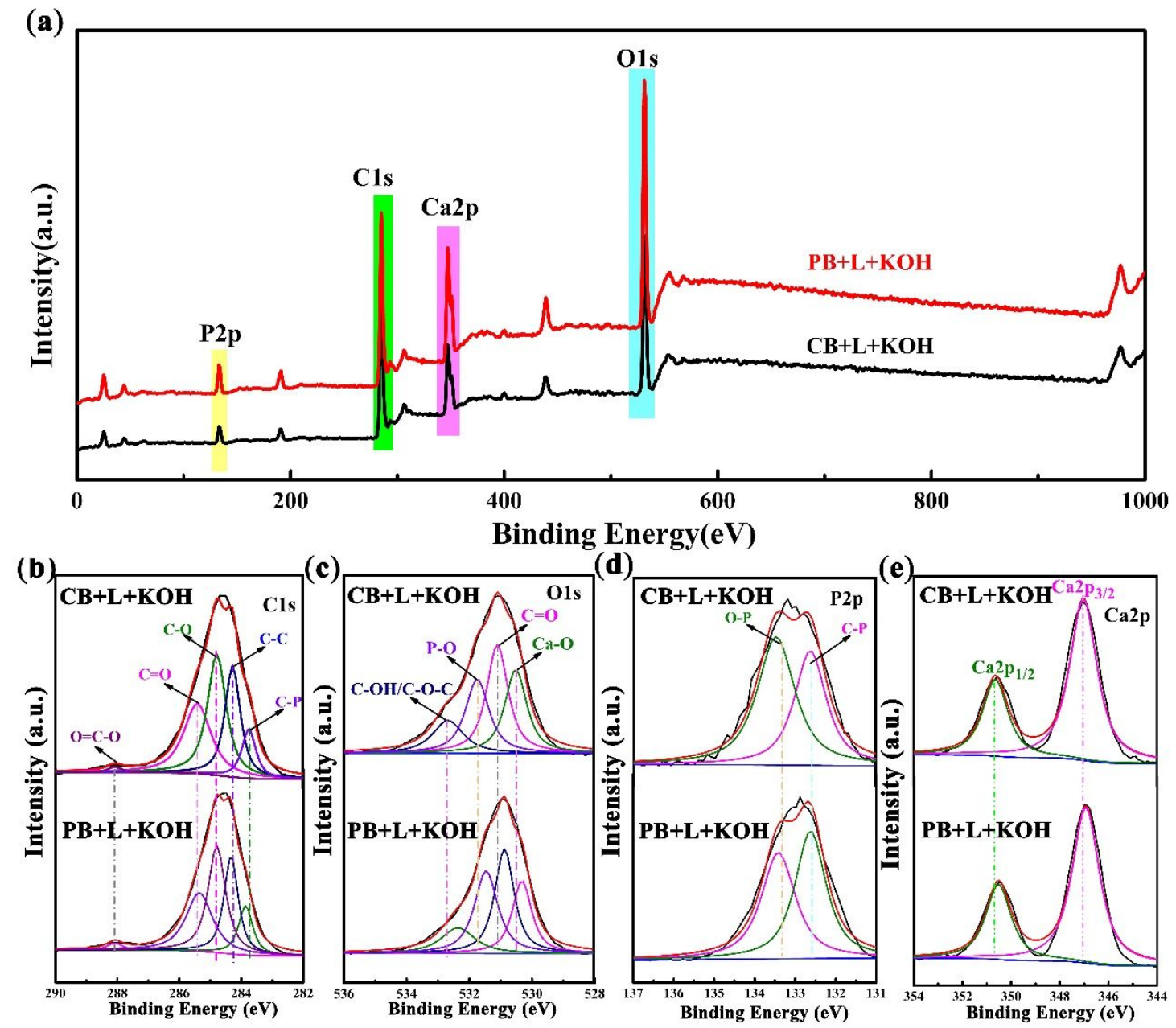

Fig. 3. Full spectrum (a) and high-resolution spectra of C1s (b), O1s (c), P2p (d), and Ca2p (e) after chicken and pig bones were etched by A-HA from leaves.

XPS and FTIR data also confirm the existence of a strong chemical interaction between A-HA and bones, in which the dissolution of bones and the morphological transformation of phosphorus is driven by thermodynamics, sufficient reaction time between organic and inorganic phases assumed. As shown in Fig. 3a and Fig. S4 (supporting information), four main strong peaks with binding energies of $290.98 \mathrm{eV}$, $539.18 \mathrm{eV}, 139.58 \mathrm{eV}$, and $356.18 \mathrm{eV}$ are easily assigned to the $\mathrm{C} 1 \mathrm{~s}, \mathrm{O} 1 \mathrm{~s}, \mathrm{P} 2 \mathrm{p}$, and $\mathrm{Ca} 2 \mathrm{p}$ orbitals, respectively, indicating that the main elements contained in the powders are $\mathrm{C}, \mathrm{O}, \mathrm{P}$, and $\mathrm{Ca}$. The proportion of each atom is listed in Table $\mathrm{S} 2$ (supporting 
information). Fig. $3 \mathrm{~b}$ presents the high-resolution fitting spectra of $\mathrm{C} 1 \mathrm{~s}$ of solid residues from bones etched by A-HA, and $\mathrm{O}-\mathrm{C}=\mathrm{O}(288.1 \mathrm{eV}), \mathrm{C}=\mathrm{O}(285.4 \mathrm{eV}), \mathrm{C}-\mathrm{O}(284.8 \mathrm{eV})$, C-C $(284.3 \mathrm{eV})$, and C-P $(283.7 \mathrm{eV})$ were deconvoluted into five peaks ${ }^{32-36}$. Obviously, a large number of oxygen-containing functional groups are found on the former bone surface (Table S3 in supporting information, $63.0 \%$ for PB and $64.0 \%$ for CB) (i.e., $\mathrm{C}-\mathrm{O}, \mathrm{C}=\mathrm{O}$, and $-\mathrm{COOH}$ ). The morphological changes may be caused by the large amount of A-HA etched into the bones, while the insoluble complex of A-HA and $\mathrm{Ca}^{2+}$ deposits on the bones surface. This is confirmed by Fig. S5 (supporting information): in the FTIR spectra of the original bones (CB and PB), a significant vibration of the $\mathrm{OH}$ peak in $\mathrm{Ca}_{5}\left(\mathrm{PO}_{4}\right)_{3}(\mathrm{OH})$ was found at $3565 \mathrm{~cm}^{-137-38}$, while this peak disappeared for the etched bones, indicating that the stable structure of $\mathrm{Ca}_{5}\left(\mathrm{PO}_{4}\right)_{3}(\mathrm{OH})$ is destroyed by A-HA and reconstructed into new compounds. In addition, bones etched by A-HA have larger peaks corresponding to $-\mathrm{C}=\mathrm{O} /-\mathrm{COOH}$ in $1613 \mathrm{~cm}^{-1}$ than the original bones $^{39-40}$. The raw bones samples have common peaks of P-O stretching at $589 \mathrm{~cm}^{-1}$, which are significantly stronger than those of the A-HA etched ones ${ }^{37}$, indicating that the anionic functional group in A-HA has a strong chemical interaction with the $\mathrm{P}-\mathrm{O}$ in the bones. Combined with the results of XRD analysis, we can conclude that phosphate ions may have exchanged in the reaction with the anionic functional groups of A-HA. There are however still some $\mathrm{Ca}_{5}\left(\mathrm{PO}_{4}\right)_{3}(\mathrm{OH})$ compounds left in the solid residues after $\mathrm{HTH}$ reaction, and other new phosphate species such as $\mathrm{Ca}_{3}\left(\mathrm{PO}_{4}\right)_{2} \cdot \mathrm{xH}_{2} \mathrm{O}$ can be postulated from XPS and XRD analysis, indicating that as-liberated phosphate ions then 
recrystallize on the surface with $\mathrm{Ca}^{2+}$ and other bone components to form new $\mathrm{P}$ minerals. This recrystallization-after-etching were already observed in the SEM images, and we also remember that the bones were converted into mechanically easy-to-break powder aggregates. In addition, elemental analysis of the raw and A-HA etched bones revealed that the percentage of $\mathrm{C}, \mathrm{H}$, and $\mathrm{O}$ elements in the etched bones was significantly higher than the corresponding values in raw bone (Table S4 in supporting information).

Further experiments were preformed to determine the content of $\mathrm{P}$ in bones $(\mathrm{CB}$ and $\mathrm{PB}$ ), and the measurements after digesting the bones showed that the content of total phosphorus (TP) in chicken bone $(17.0 \mathrm{mg} / \mathrm{g}$ in solution) and pork bone $(15.4 \mathrm{mg} / \mathrm{g}$ in solution) (details shown in Supporting Information). This relatively high P content in the bones can be advantageously used for fertilizer production. As shown in Fig. 4, for the series of $\mathrm{CB}+\mathrm{L}+\mathrm{KOH}$ samples, the amount of etching soluble $\mathrm{P}$ gradually increases as the reaction time increases. Interestingly, the resultant bone residues gradually decreased as reaction time was prolonged (16-48 h), even completely digested. In general, protein after $\mathrm{HTH}$ reaction is not protein anymore $\left(200{ }^{\circ} \mathrm{C}, 16-48\right.$ h). Protein firstly hydrolyses at $180{ }^{\circ} \mathrm{C}$, then generates amino acides which will recombine with lignin to form humic acid or condense into heterocycles. The maximum values in these standard solutions are $24.24 \pm 1.44 \mathrm{mg} / \mathrm{L}$ for DP, and $11.68 \pm 0.84 \mathrm{mg} / \mathrm{L}$ for AP after $24 \mathrm{~h}$. When compared to $\mathrm{CB}+\mathrm{R}+\mathrm{KOH}$ samples, the amount of soluble $\mathrm{P}$ resulted from the bones was the largest after $24 \mathrm{~h}$. We find their considerable P 
dissolution (DP, AP, and DP recovery rates were $96.79 \pm 2.64 \mathrm{mg} / \mathrm{L}, 77.69 \pm 0.10 \mathrm{mg} / \mathrm{L}$, and $6.36 \%$, respectively). For $\mathrm{PB}+\mathrm{L}+\mathrm{KOH}$ samples, after $24 \mathrm{~h}$, DP value in these standard solutions was $15.25 \pm 0.92 \mathrm{mg} / \mathrm{L}$ and AP value was $7.96 \pm 0.23 \mathrm{mg} / \mathrm{L}$. Worth noting, amount of soluble $\mathrm{P}$ produced by $\mathrm{PB}+\mathrm{R}+\mathrm{KOH}$ samples was dominant (DP, $\mathrm{AP}$, and DP recovery rates were $63.81 \pm 5.78 \mathrm{mg} / \mathrm{L}, 42.05 \pm 4.20 \mathrm{mg} / \mathrm{L}$, and $4.77 \%$ ). The above results indicate that the A-HA derived from root has a stronger ability to etch bone than the A-HA derived from leaf. The DP recovery rates for all samples are listed in Table S5 (supporting information).

In order to expand experiments to a widely applicable plant biomass source, the former model biomasses (leaves and roots) and the alkaline additive (KOH) in the experiment were replaced by typical waste corn stalks (CS), available in huge amounts as waste about 300 million tons per year in China ${ }^{41}$, and combustion waste alkaline ash (AA) to realize a whole sustainable solid waste starting situation. Since the alkali produced by the action of $\mathrm{AA}$ and $\mathrm{Ca}(\mathrm{OH})_{2}$ is relatively weak, the hydrothermal reaction time was set to $48 \mathrm{~h}$. Even under such real-life conditions, a large amount of $\mathrm{P}$ was dissolved (Chicken bone: DP is $15.25 \pm 0.92 \mathrm{mg} / \mathrm{L}$, AP is $6.85 \pm 1.01 \mathrm{mg} / \mathrm{L}$; Pork bone: DP is $18.08 \pm 1.04 \mathrm{mg} / \mathrm{L}$, AP is $2.86 \pm 0.04 \mathrm{mg} / \mathrm{L}$ ), implying that combustion ashes and chalk are suitable candidates to replace $\mathrm{KOH}$. 


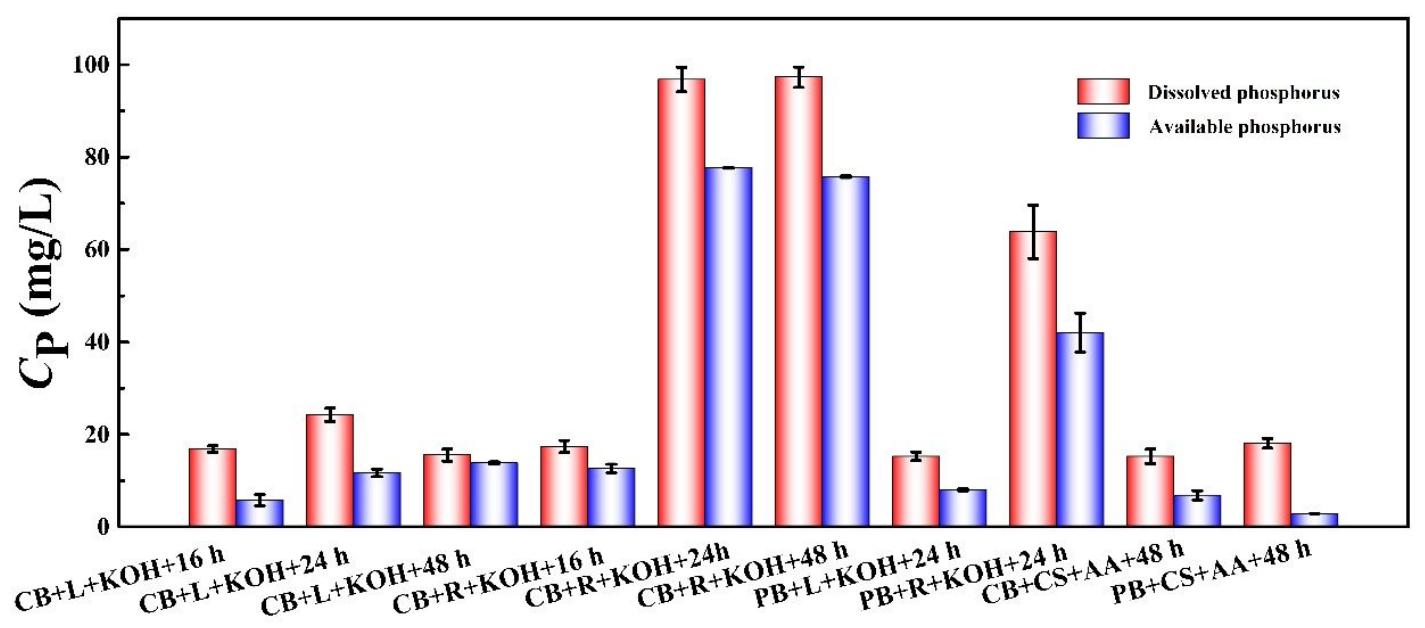

\section{Samples}

Fig. 4. Comparison of dissolved phosphorus and available phosphorus after different A-HA

(leaves, roots and corn stalks) etched different animal bones (CB and PB).

Release of DP and AP creates a new, sterile, non-unpleasant smelling system for fertilization which is derived from kitchen waste. To further study the effect of soluble P extracted from bones on soil fertility and plant growth, samples of CS + B (chicken and pig bones) + AA were chosen as examples for further pot experiments. The products were applied in planting experiments on barren soil collected from abandoned land. From previous studies we know that this standard barren soil has a TP content of $474.9 \mathrm{mg} / \mathrm{kg}(27.0 \mathrm{mg} / \mathrm{kg}$ for AP), which is less than that of natural fertile black soil, which is $900.0 \mathrm{mg} / \mathrm{kg}(180.0 \mathrm{mg} / \mathrm{kg} \text { for } \mathrm{AP})^{19}$, ${ }^{42}$. This may be due to soil $\mathrm{P}$ mineralization, less soil organic matter, and poor $\mathrm{P}$ cycles in the ecosystem ${ }^{43}$. In pot experiments, adding bones $\mathrm{P}$ fertilizer containing a certain amount of AP to this soil significantly promotes the growth of seedlings. As shown in Fig. 5a, after 22-day cultivation, the corn seedlings were cultivated for a total of 22 days. After the corn seeds were planted, the growth status of the corn seedlings was photographed regularly 
(intervals of $3,8,11$, and 22 days), indicating that growth on bone-reinforced soil was significantly better than barren soil (control group). After 22 days, the corn seedlings were pulled out and the lengths of corn seedling roots, stems and plants, and their fresh and dry weights were measured (Fig. 5b-d). The results showed that the growth of corn biomass is significantly better on artificial fertile soil than those of the control group. The average height of seedings grown on the two artificial fertile soils was $50.0 \mathrm{~cm}$ (pig bone) and $44.5 \mathrm{~cm}$ (chicken bone), which is much larger than the average height of the plants grown on control group $(35.3 \mathrm{~cm})$. In addition, the root length, fresh plant weight, and dry plant weight of plants grown on artificial fertile soils showed obvious improvements (Fig. 5b-d), quantifying that the restructured P extracts from bones have in these experiments a positive effect on plant growth. Artificial fertile soils contain considerable AP $40.0 \mathrm{mg} / \mathrm{kg}$ (CB extracted P modified soil) and $41.6 \mathrm{mg} / \mathrm{kg}$ (PB extracted P modified soil), which are much higher than the poor soil $27.0 \mathrm{mg} / \mathrm{kg}$ (control) and artificial fertile soils, continuously providing nutrients to plants (Fig. 5e). As shown in Fig. 5e, after 11 days of corn growth, AP content still remained at 29.2 $\mathrm{mg} / \mathrm{kg}$ (CB extracted P modified soil) and $25.8 \mathrm{mg} / \mathrm{kg}$ (PB extracted P modified soil), i.e. there is a continuous P-transformation activated and ongoing. 

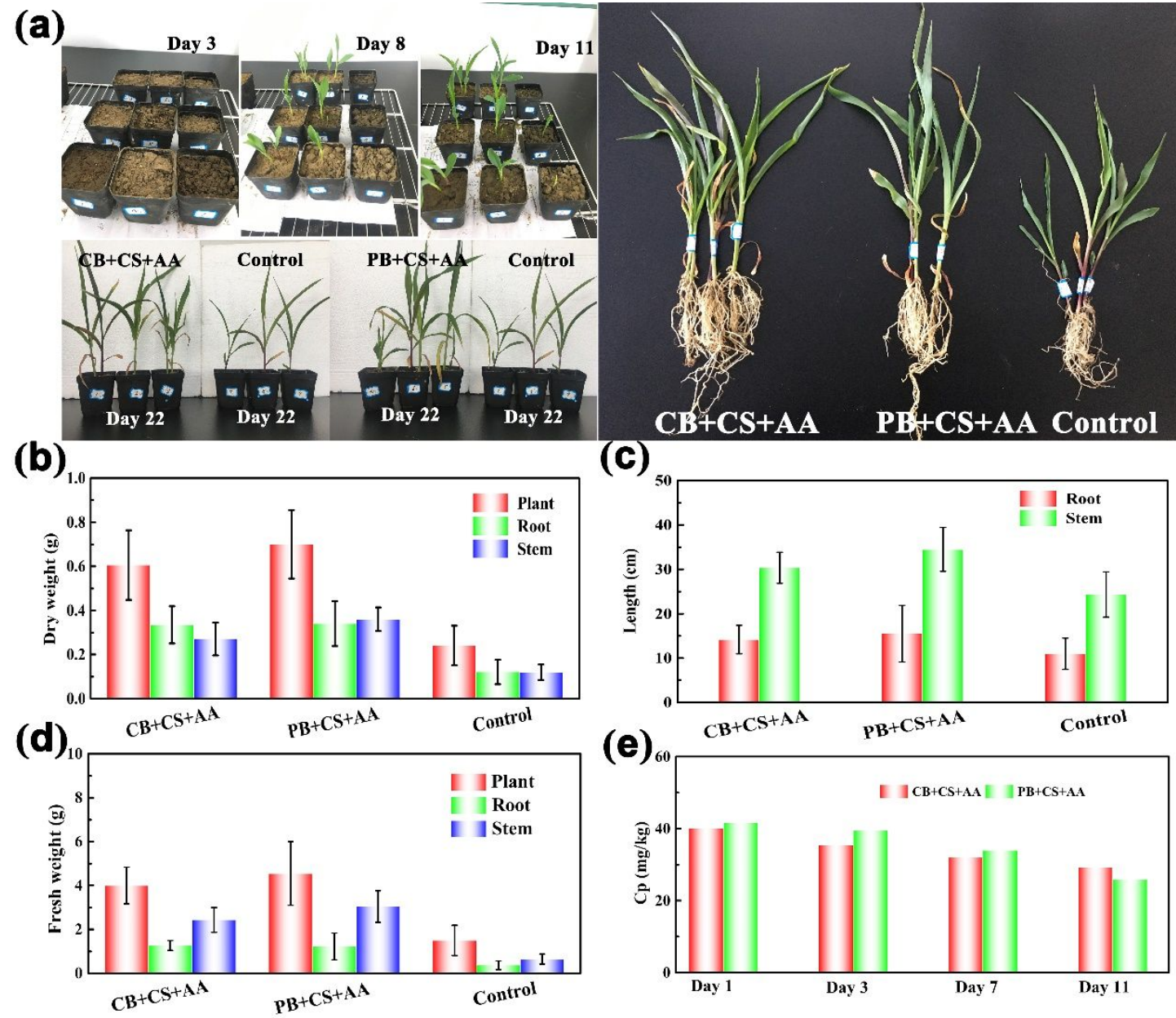

Fig. 5. Comparison of 22 days of seeding growth before and after modification of artificial fertile soil.

(including recording changes in AP (b) in artificial fertile soil for 11 day)

\section{CONCLUSION}

Ahead of the background that the world 's phosphate mineral deposits become depleted in the near future, as well as there are large amounts of animal bones from food production and kitchen wastes treated unreasonably, we propose a feasible approach to transform the insoluble $\mathrm{P}$ present in animal bones via artificial humic acid (A-HA) treatment into a remineralized dispersion for plant cultivation. Various analytical techniques were applied to study the etching mechanisms of the bones by AHA samples. We found that the morphological changes of bones and the amount of 
phosphorus released are not only due to ion exchange with the anionic functional groups of A-HA, but also massively due to remineralization into new, more soluble calcium phosphate species, stabilized by A-HA.

In addition, the practicability of this "closing-the-phosphate-cycle" approach was confirmed by planting experiments. The introduction of the newly obtained digestible phosphate- and available phosphate in experiments analyzing the growth of corn seedlings gave significant promotion of plant growth. The average height of seedings grown on the two reinforced soils were $50.0 \mathrm{~cm}$ and $44.5 \mathrm{~cm}$, which was much larger than the average height of the seeding grown on control group $(35.3 \mathrm{~cm})$. Obviously, the proposed technique is not only simple and convenient, but also hygienic and chemically save, and may contribute to improved food safety in the future. The current data of course only set the base for more stringent farmland tests, which also may reveal some long term advantages of the added humic acid for farmland texture and agriculture.

\section{SUPPORTING INFORMATION}

Details of fabrication of A-HA and data analysis of soil and bone phosphorus; Images of original bones; Images of $\mathrm{FePO}_{4}$ treated by $\mathrm{HTH}$ progress with the corresponding elemental mapping; Images of chicken bone etched with A-HA and the corresponding elemental mapping; Full spectrum and high-resolution XPS spectra of C1s, O1s and P2p of solid residues from bones etched by A-HA; FTIR spectra of bones and resultant residues etched by A-HA; Content of acidic functional groups of A-HA extracted from different biomasses; Atomic ratios of resultant residues from bones etched by A-HA; 
Area ratios of each component in resultant residues from bones etched by A-HA; Elemental analysis of original bones and the corresponding solid residues after HTH progress; DP recovery rate of bones etched by different A-HA under different conditions.

\section{AUTHOR INFORMATION}

\section{Corresponding Author}

Fan Yang: telephone No: +86 451 55191528; fax No: +86 451 55191528; email: yangfanneau@,163.com.

Markus Antonietti: email: Markus.Antonietti@mpikg.mpg.de.

\section{Notes}

The authors declare no competing financial interest.

\section{ACKNOWLEDGMENTS}

The authors acknowledge the financial support from Longjiang Scholars for young scientist, University Nursing Program for Young Scholars with Creative Talents in Heilongjiang Province (UNPYSCT-2017018), Natural Science Foundation of Heilongjiang Province of China (QC2018019).

\section{ABBREVIATIONS}

A-HA, artificial humic acid; A-FA, artificial fulvic acid; HTH, hydrothermal humification; DP, soluble phosphorus; TP, total phosphorus; AP, available phosphorus; $\mathrm{CB}$, chicken bones; PB, pork bones; CS, corn stalks; L, eucalyptus leaves; R, tea roots; AA, alkali ash; R-HA, artificial humic acid from roots; L-HA, artificial humic acid 
from leaves; W-HA, artificial humic acid from wood; CS-HA, artificial humic acid from corn straw;

\section{REFERENCES}

1. Goldhammer, T.; Brüchert, V.; Ferdelman, T. G.; Zabel, M., Microbial sequestration of phosphorus in anoxic upwelling sediments. Nat. Geosci. 2010, 3 (8), 557-561. https://doi.org/10.1038/ngeo913.

2. Liu, T. Y.; Huang, T. K.; Yang, S. Y.; Hong, Y. T.; Huang, S. M.; Wang, F. N.; Chiang, S. F.; Tsai, S. Y.; Lu, W. C.; Chiou, T. J., Identification of plant vacuolar transporters mediating phosphate storage. Nat. Commun. 2016, 7, 11095.

https://doi.org/10.1038/ncomms 11095.

3. Gilbert, N., The disappearing nutrient: phosphate-based fertilizers have helped spur agricultural gains in the past century, but the world may soon run out of them. Natasha Gilbert investigates the potential phosphate crisis. Nature 2009, 461 (7267), 1041-1041. https://doi.org/10.1038/4611041b

4. Kratz, S.; Schnug, E., Rock phosphates and $\mathrm{P}$ fertilizers as sources of U contamination in agricultural soils. In Uranium in the environment, Springer: 2006; pp 57-67. https://doi-org-443--bjtu.naihes.cn/10.1007/3-540-28367-6_5

5. Schnug, E.; Birke, M.; Costa, N.; Knolle, F.; Fleckenstein, J.; Panten, K.; Lilienthal, H.; Haneklaus, S., Uranium in German mineral and tap waters. Loads and Fate of fertilizer-derived uranium. Backhuys Publishers, Leiden. ISBN/EAN 2008, 978-90. https://www.semanticscholar.org/paper/Loads-and-Fate-of-Fertilizer-derived-Uranium- 


\section{Kok-Schnug/a172e494fb6cd744f1342343114a40b5f1b45a25}

6. Shen, J.; Yuan, L.; Zhang, J.; Li, H.; Bai, Z.; Chen, X.; Zhang, W.; Zhang, F., Phosphorus dynamics: from soil to plant. Plant. Physiol. 2011, 156 (3), 997-1005. https://doi.org/10.1104/pp.111.175232.

7. Penuelas, J.; Poulter, B.; Sardans, J.; Ciais, P.; Van Der Velde, M.; Bopp, L.; Boucher, O.; Godderis, Y.; Hinsinger, P.; Llusia, J.; Nardin, E.; Vicca, S.; Obersteiner, M.; Janssens, I. A., Human-induced nitrogen-phosphorus imbalances alter natural and managed ecosystems across the globe. Nat. Commun. 2013, 4 (1), 1-10.

https://doi.org/10.1038/ncomms3934

8. Augusto, L.; Achat, D. L.; Jonard, M.; Vidal, D.; Ringeval, B., Soil parent materialA major driver of plant nutrient limitations in terrestrial ecosystems. Global. Change. Biol. 2017, 23 (9), 3808-3824. https://doi.org/10.1111/gcb.13691.

9. Hou, E.; Tang, S.; Chen, C.; Kuang, Y.; Lu, X.; Heenan, M.; Wen, D., Solubility of phosphorus in subtropical forest soils as influenced by low-molecular organic acids and key soil properties. Geoderma 2018, 313, 172-180.

https://doi.org/10.1016/j.geoderma.2017.10.039.

10. Peter M. V; Stephen, P.; Benjamin, Z. H.; C., O. A., Terrestrial phosphorus limitation: mechanisms, implications, and nitrogen-phosphorus interactions. Ecol. Appl. 2010, 20 (1), 5-15. https://doi.org/10.1890/08-0127.1

11. Yang, F.; Zhang, S.; Sun, Y.; Tsang, D. C.; Cheng, K.; Ok, Y. S., Assembling biochar with various layered double hydroxides for enhancement of phosphorus 
recovery. J. Hazard. Mater. 2019, 365, 665-673.

https://https://doi.org/10.1016/i.jhazmat.2018.11.047

12. Yang, F.; Antonietti, M., Artificial humic acids: Sustainable materials against climate change. $A d v$. Sci. 2020, 7 (5). https://doi.org/10.1002/advs.201902992

13. Yang, F.; Zhang, S.; Fu, Q.; Antonietti, M., Conjugation of artificial humic acids with inorganic soil matter to restore land for improved conservation of water and nutrients. Land. Degrad. Dev. 2019, 3343. https://doi.org/10.1002/1dr.3486

14. Kramer, R. W.; Kujawinski, E. B.; Hatcher, P. G., Identification of black carbon derived structures in a volcanic ash soil humic acid by fourier transform ion cyclotron resonance mass spectrometry. Environ. Sci. Technol. 2004, 38 (12), 3387-3395. https://doi.org/10.1021/es030124m

15. Yang, Z.; Kappler, A.; Jiang, J., Reducing capacities and distribution of redoxactive functional groups in low molecular weight fractions of humic acids. Environ.

Sci. Technol. 2016, 50 (22), 12105-12113.

http://h-s.doi.org.qlu.naihes.cn/10.1021/acs.est.6b02645

16. Yang, F.; Antonietti, M., The sleeping giant: A polymer View on humic matter in synthesis and applications. Prog. Polym. Sci. 2020, 100, 101182.

https://doi.org/10.1016/j.progpolymsci.2019.101182

17. Borch, T.; Kretzschmar, R.; Kappler, A.; Cappellen, P. V.; Ginder-Vogel, M.; Voegelin, A.; Campbell, K., Biogeochemical redox processes and their impact on contaminant dynamics. Environ. Sci. Technol. 2009, 2010 (44), 15-23. 
https://doi.org/10.1021/es9026248

18. Melton, E. D.; Swanner, E. D.; Behrens, S.; Schmidt, C.; Kappler, A., The interplay of microbially mediated and abiotic reactions in the biogeochemical Fe cycle. Nat. Rev. Microbiol. 2014, 12 (12), 797-808. https://doi.org/10.1038/nrmicro3347

19. Yang, F.; Zhang, S.; Song, J.; Du, Q.; Li, G.; Tarakina, N. V.; Antonietti, M., Synthetic Humic Acids Solubilize Otherwise Insoluble Phosphates to Improve Soil Fertility. Angew. Chem. Int. Ed. 2019, 58 (52), 18813-18816.

https://doi.org/10.1002/ange.201911060

20. Seng, B.; Hirayama, K.; Katayama-Hirayama, K.; Ochiai, S.; Kaneko, H., Scenario analysis of the benefit of municipal organic-waste composting over landfill, Cambodia. J. Environ. Manage. 2013, 114, 216-224.

https://doi.org/10.1016/j.jenvman.2012.10.002

21. Someus, E.; Pugliese, M., Concentrated phosphorus recovery from food grade animal bones. Sustainability 2018, 10 (7), 2349. https://doi.org/10.3390/su10072349

22. Postma J; Clematis F; Nijhuis E H; Someus, E., Efficacy of four phosphatemobilizing bacteria applied with an animal bone charcoal formulation in controlling Pythium aphanidermatum and Fusarium oxysporum f.sp. radicis lycopersici in tomato. Biol. Control. 2013, 67 (2), 284-291. https://doi.org/10.1016/j.biocontrol.2013.07.002 23. Darwish, M.; Aris, A.; Puteh, M. H.; Jusoh, M. N. H.; Kadir, A. A., Waste bones ash as an alternative source of $\mathrm{P}$ for struvite precipitation. J. Environ. Manage. 2017, 203 861-866. https://doi.org/10.1016/j.jenvman.2016.02.033 
24. Gong, Y.; Guo, Z.; He, L.; Li, J., Identification of maize genotypes with high tolerance or sensitivity to phosphorus deficiency. J. Plant. Nutr. 2011, 34 (9), 12901302. https://doi.org/10.1080/01904167.2011.580816

25. Yang, F.; Zhang, S.; Cheng, K.; Antonietti, M., A hydrothermal process to turn waste biomass into artificial fulvic and humic acids for soil remediation. Sci. Total. Environ. 2019, 686, 1140-1151. https://doi.org/10.1016/j.scitotenv.2019.06.045

26. Du, Q.; Li, G.; Zhang, S.; Song, J.; Zhao, Y.; Yang, F., High-dispersion zero-valent iron particles stabilized by artificial humic acid for lead ion removal. J. Hazard. Mater. 2019, 383, 121170. https://doi.org/10.1016/j.jhazmat.2019.121170

27. Du, Q.; Zhang, S.; Song, J.; Zhao, Y.; Yang, F., Activation of porous magnetized biochar by artificial humic acid for effective removal of lead ions. J. Hazard. Mater. 2020, 389, 122115. https://doi.org/10.1016/j.jhazmat.2020.122115

28. Jiang, L.; Li, Y.; Shao, Y.; Zhang, Y.; Han, R.; Li, S.; Wei, W., Enhanced removal of humic acid from aqueous solution by novel stabilized nano-amorphous calcium phosphate: Behaviors and mechanisms. Appl. Surf. Sci. 427, 965-975.

https://doi.org/10.1016/j.apsusc.2017.08.104

29. Chakraborty, R.; Bepari, S.; Banerjee, A., Application of calcined waste fish (Labeo rohita) scale as low-cost heterogeneous catalyst for biodiesel synthesis. Bioresour. Technol. 2011, 102 (3), 3610-8.

https://doi.org/10.1016/j.biortech.2010.10.123

30. Farooq, M.; Ramli, A.; Naeem, A., Biodiesel production from low FFA waste 
cooking oil using heterogeneous catalyst derived from chicken bones. Renew. Energ. 2015, 76, 362-368. https://doi.org/10.1016/j.renene.2014.11.042

31. Fukui, K.; Arimitsu, N.; Kidoguchi, S.; Yamamoto, T.; Yoshida, H., Synthesis of calcium phosphate hydrogel from waste incineration fly ash and bone powder. $J$. Hazard. Mater. 2009, 163 (1), 391-395. https://doi.org/10.1016/j.jhazmat.2008.06.103

32. Yang, F.; Zhang, S.; Li, H.; Li, S.; Cheng, K.; Li, J.; Tsang, D. C. W., Corn strawderived biochar impregnated with $\alpha-\mathrm{FeOOH}$ nanorods for highly effective copper removal. Chem. Eng. J. 2018, 348, 191-201. https://doi.org/10.1016/j.cej.2018.04.161

33. Yang, F.; Zhang, S.; Sun, Y.; Du, Q.; Song, J.; Tsang, D. C. W., A novel electrochemical modification combined with one-step pyrolysis for preparation of sustainable thorn-like iron-based biochar composites. Bioresour. Technol. 2019, 274, 379-385. https://doi.org/10.1016/j.biortech.2018.10.042

34. Song, J.; Zhang, S.; Li, G.; Du, Q.; Yang, F., Preparation of montmorillonite modified biochar with various temperatures and their mechanism for $\mathrm{Zn}$ ion removal. J. Hazard. Mater. 2020, 391, 121692. https://doi.org/10.1016/j.jhazmat.2019.121692

35. Zhang, S.; Du, Q.; Sun, Y.; Song, J.; Yang, F.; Tsang, D. C. W., Fabrication of Lcysteine stabilized $\alpha-\mathrm{FeOOH}$ nanocomposite on porous hydrophilic biochar as an effective adsorbent for $\mathrm{Pb}^{2+}$ removal. Sci. Total Environ. 2020, 720, 137415. https://doi.org/10.1016/j.scitotenv.2020.137415

36. Zhang, S.; Song, J.; Du, Q.; Cheng, K.; Yang, F., Analog synthesis of artificial humic substances for efficient removal of mercury. Chemosphere 2020, 250, 126606. 
https://doi.org/10.1016/j.chemosphere.2020.126606

37. Lopes, C. D. C. A.; Limirio, P. H. J. O.; Novais, V. R.; Dechichi, P., Fourier transform infrared spectroscopy (FTIR) application chemical characterization of enamel, dentin and bone. Appl. Spectrosc. Rev. 2018, 53 (9), 747-769.

https://doi.org/10.1080/05704928.2018.1431923

38. Rehman, I.; Bonfield, W., Characterization of hydroxyapatite and carbonated apatite by photo acoustic FTIR spectroscopy. J. Mater. Sci: mater. M. 1997, 8 (1997), 1-4. https://doi.org/10.1023/a:1018570213546

39. Amir, S.; Jouraiphy, A.; Meddich, A.; Gharous, M. E.; Winterton, P.; Hafidi, M., Structural study of humic acids during composting of activated sludge-green waste: elemental analysis, FTIR and 13C NMR. J. Hazard. Mater. 2010, 177 (1-3), 524-529. https://doi.org/10.1016/j.jhazmat.2009.12.064

40. Zhang, S.; Du, Q.; Cheng, K.; Antoniettic, M.; Yang, F., Efficient phosphorus recycling and heavy metal removal from wastewater sludge by a novel hydrothermal humification-technique. Chem. Eng. J. 2020, 394, 12483.

https://doi.org/10.1016/j.cej.2020.124832

41. Li, Y.; Xing, B.; Wang, X.; Wang, K.; Wang, S., Nitrogen-doped hierarchical porous biochar derived from corn stalks for phenol enhanced adsorption. Energ. Fuel. 2019, 33 (12), 12459-12468.

http://h-s.doi.org.qlu.naihes.cn/10.1021/acs.energyfuels.9b02924

42. Atere, C. T.; Ge, T.; Zhu, Z.; Liu, S.; Huang, X.; Shibsitova, O.; Guggenberger, 
G.; Wu, J., Assimilate allocation by rice and carbon stabilisation in soil: effect of water management and phosphorus fertilisation. Plant. Soil. 2018, 445, 153-167. https://doi.org/10.1007/s11104-018-03905-x

43. Quinton J. N ; Govers G ; Oost, K. V.; Bardgett, R. D., The impact of agricultural soil erosion on biogeochemical cycling. Nat. Geosci. 2010, 3, 311-314.

https://doi.org/10.1038/ngeo838 